\title{
La perspectiva de género en la recepción de telenovelas
}

\section{Genre perspective in the reception of soap operas}

\author{
José Ignacio Aguaded Gómez (Universidad de Huelva) \\ Juan Bautista Romero Carmona (Universidad de Huelva)

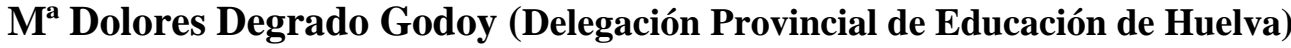 \\ http://dx.doi.org/10.12795/AdMIRA.2010.01.06
}

\section{Resumen}

La igualdad entre hombres y mujeres se ha convertido hoy en día en uno de los valores prioritarios o que más relevancia está adquiriendo en el actual contexto socio-mediático que vivimos. No cabe duda que el mundo televisivo es un importante agente de socialización, cuantitativa y cualitativamente, con el que conviven diariamente niños y niñas. En este sentido, las telenovelas son uno de los géneros televisivos con mayor visionado y preferencia por parte de niños y jóvenes. Este trabajo recoge una síntesis breve de una investigación realizada en un centro escolar durante el año 2007, reflejando no sólo los hábitos de consumo televisivo de niñas y niños de 11 y 12 años, sino también sus estereotipos de género.

\section{Descriptores}

Educación en valores, valores de género, televisión, telenovelas, consumo televisivo.

\begin{abstract}
Nowadays, equality between men and women has become one of the main values due to the present circumstances we all live. Also, the world of the television is an important socialization agent which boys and girls confront every day, both quantitatively and qualitatively. Among others, one of the television programmes children face daily are soap operas series. This article is intended to present the results obtained after a school research in 2007 and it is pretended to reflect eleven and twelve year old young children' consumerism habits.
\end{abstract}

Key words

Education in values, genre values, television soap operas, television consuming.

\section{Contextualización}

En todo contexto social existe siempre un conjunto más o menos uniformado de valores arquetipos que se caracterizan por su variabilidad temporal y sus diferentes niveles de trascendencia, adquiriendo algunos más relevancia que otros. Los valores tienen una poderosa influencia en el comportamiento humano, pues generan actitudes las cuales, a su vez, van a determinar la conducta social de las personas. Teniendo en cuenta las 
actuales circunstancias en las que vivimos, la igualdad entre hombres y mujeres se ha convertido en uno de los valores prioritarios desde un punto de vista político-social.

La escuela, como institución social y educativa, tiene un importante papel en el proceso de formación de estos valores, de hábitos, actitudes y comportamientos que faciliten la convivencia de las personas. Por ello, el centro escolar ha de ser un espacio donde se recree la cultura, no sólo donde ésta se transmita de forma mecánica y acrítica. Nuestra sociedad ha reglamentado reformas educativas para impulsar la igualdad de oportunidades educativas de niñas y niños. Pero existen otras formas de socialización y modelización cultural, no estrictamente educativas o familiares, como la proveniente de los medios de comunicación, y dentro de éstos, la televisión es el más accesible para niños y niñas, convirtiéndose en un pilar básico en el desarrollo intelectual, conductual y emocional de la población infantil.

La televisión es un referente constante para los niños y niñas, con ella conviven gran cantidad de tiempo al día y constituye una fuente potencial de aprendizaje para el menor. El mundo televisivo es un importante agente de socialización para los menores, cuantitativa y cualitativamente. Son múltiples los programas televisivos a los que se enfrentan niños y niñas. Entre ellos se halla la telenovela, la cual es objeto de nuestro estudio. La telenovela es un fenómeno de entretenimiento basado en el melodrama. A lo largo de su existencia ha sido cuestionada y encasillada a una forma mediocre de entretener a los telespectadores (Aguaded, 1993). Se ha debatido ampliamente el «raiting» y el éxito de las mismas. Pero el objeto de este trabajo de investigación es contribuir a señalar la representación de los sexos que se ofrece a niños y niñas a través de la recepción de telenovelas, que refleja y recrea la desigualdad entre los géneros, contribuyendo a configurar un orden simbólico patriarcal, una representación que reconstruye la supremacía masculina.

Este trabajo también pretende reflejar los hábitos de consumo de telenovelas de niñas y niños de 11 y 12 años, que explica la influencia o los efectos del entretenimiento televisivo, al suponer un tipo de interacción diaria y, a la vez, cómo esa recepción confirma, desde la cultura lúdica televisiva, la socialización diferencial de género, 
contribuyendo al establecimiento de modelos sociales $\mathrm{y}$, por tanto, identidad $\mathrm{y}$ expectativas vitales desiguales para niñas y niños.

La puesta en marcha en Andalucía del I Plan de Igualdad entre hombres y mujeres, el primero en esta temática social a nivel nacional, hace necesario la formación y concienciación ante el tema, así como la necesidad de estudios de género donde fundamentarse para llevar a cabo diferentes iniciativas en orden a alcanzar una mayor igualdad de género entre hombres y mujeres.

Abordamos, en consecuencia, en este trabajo dos bloques diferenciados, una revisión de antecedentes con las bases conceptuales a partir de las cuales se fundamenta la investigación; y una segunda parte, dedicada a presentar una investigación realizada sobre el consumo de telenovelas y la desigualdad de género que la recepción de éstas conllevan en niños y niñas preadolescentes.

\subsection{Valores de género}

Según Encabo y López (2004), uno de los temas trascendentales en este comienzo de siglo XXI es el referido a las diferencias de género, a los problemas que se derivan de la desigualdad y, cómo no, la violencia existente entre mujeres y varones, ya sea ésta de índole física o bien psíquica. Esta situación viene dada por la configuración social que se establece como marco de referencia para las actuaciones de las personas. No hay duda que el ascenso de la notoriedad de las mujeres dentro del entorno social es un hecho, y tal vez por ello nos genera un mayor rubor la denuncia de las injusticias relacionadas con la diferencias de género, pero no por ello debemos interpretar que éste es un hecho característico de los tiempos en los cuales vivimos. No, no lo es ya que las cuestiones de género son algo que ha trascendido a lo largo de la historia humana y es algo que siempre ha existido - la desigualdad - pero por los condicionantes sociales no era algo que pudiera ser instado al cambio o bien simplemente reseñado. Entre ellos encontramos el sexismo o diferencias de género, y es por ello por lo que merece la pena reflexionar sobre las situaciones que se conciben a partir del planteamiento de la temática. 
En el I Plan de Igualdad entre hombres y mujeres en educación (2005: 40), se dice que «un gran cambio que caracteriza nuestra época, y que afecta de forma singular a la vida de las mujeres y de los hombres, es la progresiva incorporación de las mujeres al trabajo remunerado y su acceso a casi todos los ámbitos de la vida pública, la educación, la política, la industria, los sindicatos, la sanidad, la justicia, etc.».

\subsection{Valores y género en la sociedad televisiva}

Los hombres y mujeres, biológicamente, nacen diferentes, pero no con una posición diferenciada. Es la sociedad la encargada de que representemos papeles diferentes; o que incorporemos pautas de configuración psíquica y social que hacen posible la diferenciación de género, a través de construcciones sociales. Así mismo, Maisch (1999) apunta que el sexo, hecho biológico, se convierte en género en la medida en que las diferencias sexuales son imaginadas o significadas por la sociedad.

Y en la sociedad actual no podemos obviar el papel mediático e influyente de los medios de comunicación de masas como agentes que refuerzan y divulgan determinadas creencias y valores tradicionales, como reflejo de las normas sociales imperantes (Balletbó, 1984). Dentro de estos medios de comunicación, la televisión es actualmente el principal narrador de historias sobre el mundo y la vida, sobre la sociedad y el ser humano. Entre muchas otras cosas, en sus narraciones va transmitiendo estereotipos diferenciados para hombres y mujeres que vamos interiorizando poco a poco, haciéndolos nuestros, hasta convertirlos en actitudes y conductas; en maneras de ser, de estar y de comportarnos en la vida (Charles, 2002).

\subsection{La educación en valores desde la perspectiva de género}

Uno de los objetivos de la educación es enseñar a adaptarse a las nuevas generaciones, a comportarse según los valores y pautas socioculturales existentes. Este proceso empieza en la familia y continúa en las escuelas, además de la influencia de la TV a la hora de transmitir dichos valores, entre otros factores.

La familia es el primer lugar donde se perpetúan los roles que la sociedad ha establecido para hombres y mujeres. Numerosos estudios nos demuestran las diferentes actitudes, 
comportamientos, actitudes etc., que tienen con sus hijos o hijas según su sexo: a las niñas se les potencia la sensibilidad, el miedo, la obediencia, la dependencia, la afectividad. A los niños la agresividad, la competitividad, la independencia...

En la escuela se sigue perpetrando la educación segregada, esto es, diferenciando lo que es apropiado para las niñas y lo que es propio para los niños. No se visibiliza lo femenino y se potencia una sola forma de entender la vida, la del género masculino. Esta circunstancia se hace palpable cuando se conduce a las niñas a adoptar actitudes agresivas y competitivas, y no valorando comportamientos cooperativos (considerados femeninos) y olvidando el componente emocional de la educación.

Y por último, no debemos olvidar, la influencia que la televisión ejerce sobre todo en niño y jóvenes a la hora de mostrar imágenes sobre hombres y mujeres, que muchas veces son estereotipadas, irreales... Muñoz y Guerreiro (2001) muestran unas propuestas desde la perspectiva de género para trabajar la diversidad desde la igualdad:

- Educar en la responsabilidad compartida.

- Facilitar y promover el acceso a las nuevas tecnologías.

- Enseñar y aprender las viejas tecnologías o tareas básicas (arreglar un enchufe, coser, etc.).

- Trabajar la afectividad como elemento educativo.

- Favorecer una adecuada autoestima.

- Elaborar un proyecto educativo común vertebrado por la filosofía coeducativa.

- Entrenar en la capacidad de escucha y la utilización de la palabra en público.

- Compartir espacios (en la línea de procurar que los espacios estén ocupados por ellos y ellas independientemente de la actividad realizada, sea dentro o fuera de la escuela).

- Realizar escuelas de madres, padres, abuelas y abuelos para poder llegar a un planteamiento común entre familias y escuela.

- Dar entrada a la diversidad familiar (no sólo existe una diversidad personal, sino también existe diversidad familiar, y habitualmente esto no es tenido en cuenta ni siquiera en las fichas o documentos que se realizan del alumnado). 
- Datos y estadísticas segregadas por sexo que nos ayuden a detectar los problemas relacionados con la desigualdad de género.

- Formación permanente e inicial del profesorado en temas de género.

- Concienciar de la importancia del reparto de tareas y responsabilidades en todos los ámbitos (valorar por igual lo privado -familiar-y lo público).

Además, de todas estas propuestas que hacen referencia sobre todo a la escuela y la familia, no debemos olvidar la educación en los medios de comunicación.

\subsection{Televisión y niños/as}

La llegada del nuevo medio tuvo por efecto cambiarles las vidas a los niños y niñas, según afirma Vilches (1993). March y García (1994: 29) apuntan que «los niños y las niñas han nacido hoy casi con la televisión bajo el brazo, y así su vida se ha ido adaptando a su ritmo, al llevar de forma espontánea el mundo a los hogares, e imponer y crear nuevas necesidades. Nunca la televisión había ocupado un lugar parecido en la vida de los niños». Asimismo opina Froufe (1998: 22) que los niños actuales viven sumergidos en el mundo fascinante de la televisión, igual que el hombre medieval vivía bajo los principios de la religión, donde la capacidad crítica, en ambos casos, adolecía de un adormecimiento estructural. Pérez Alonso (1994: 186) advierte que son «numerosos los datos que demuestran que es innegable el protagonismo alcanzado por la televisión en la vida de los niños».

Los niños crecen bajo el influjo directo de medios como la televisión, como nos sugiere Sander (1990: 24): «Niños y jóvenes participan ya desde muy pronto con ayuda de los medios de comunicación en el mundo adulto de la política, las catástrofes y las diferentes culturas. Su conocimiento ha cambiado: saben mucho más del mundo de los adultos, lo conocen gracias a la televisión y a los medios de comunicación, incluso antes de ser capaces de experimentarlos por si mismos».

\subsection{Las telenovelas}

Parece ser que estamos asistiendo al renacer de un fenómeno que arrasó a finales de los ochenta y principios de los noventa. Alguien habrá que aún se acuerde de aquella 
inocente muchacha sin padres que pasa una vida... Cristal. El fenómeno televisivo de los culebrones va más allá. La banda sonora es también un objeto de adoración por parte de seguidores y seguidoras (la gran mayoría de la audiencia son mujeres). Entre estos seguidores y seguidoras no podemos obviar que se encuentra la población infantil. Son numerosos los niños y niñas que tararean la banda sonora de alguna telenovela de moda, o que comentan sus historias. ¿Qué está pasando?, ¿dónde está el éxito de estas apasionadas historias?, ¿serán los cuerpos?, ¿será la intensidad del argumento? La respuesta está en la audiencia, que igual que encumbra un programa, lo puede hacer descender al momento.

La telenovela «es un género que forma parte de la dinámica cultural de una sociedad y tiene una finalidad mediática porque funciona dentro de un sistema productivo concreto, atiende a las lógicas del consumo y reproduce al mismo tiempo esquemas culturales. Este género utiliza las diferentes expresiones de la cultura como: la música, el teatro popular, la religiosidad y la vida cotidiana de sus personajes para establecer procesos comunicacionales y generar diferentes lecturas por las audiencias» (Molina y Carvajal, 1999: 2).

\subsubsection{Los valores de género en las telenovelas}

Blanca de Lizaur (1999: 153-154), experta en literatura popular y estudiosa del género telenovela, afirma que ésta es transmisora de los valores que una sociedad tiene y desea preservar: «Para sobrevivir en un lugar dado, es necesario apoyarse en las estrategias que le han funcionado a quienes antes que nosotros han sobrevivido en ese mismo lugar». Para esta autora es indiscutible que la telenovela transmite modelos y forja estereotipos. ¿Significa esto que las telenovelas influyen en niños y adultos? Claro es que sí, y no sólo para bien, sino también para mal (naturalmente el grado variará de una obra a otra, y de una persona a otra). El mecanismo es sencillo: la telenovela (como toda la literatura) hace que odiemos o amemos determinados comportamientos, por la manera como los muestra. Si nos muestra el sufrimiento, miseria y desorientación de un viudo y sus hijos, después de que un rufián asesinó a la madre, nos comprometerá emocionalmente a no repetir el comportamiento del asesino; nos mostrará, por las consecuencias, que matar es un comportamiento destructivo. 
Entre los valores que la telenovela transmite a los telespectadores están los valores de género, como nos comentan Muñoz, Asqueta, y Martínez, (2004: 9) que «la telenovela, al igual que otros discursos mediáticos, actúa como un freno que mantiene al público al margen de la participación en las transformaciones sociales y niega, al fomentar la antidemocracia, la posibilidad de que ciertos sectores se autodeterminen, como es el caso de la mujer, de los marginados, de las minorías étnicas y logren adquirir el status que legítimamente les corresponde en la sociedad y la vida».

La mujer que aparece en la telenovela busca al hombre casi perfecto; mujer sumisa, obediente, que acepta que éste se involucre con otras mujeres, pero no al contrario, de lo cual sería juzgada, rechazada hasta el final de la telenovela donde sería perdonada: «En estos tipos de mujeres, están al mismo tiempo, encarnados los valores de nuestra sociedad: obediencia, amor, fidelidad, paciencia, resignación y toda la lista de virtudes teologales que no cesan de multiplicarse en la compleja vida moderna. Valores tanto más relativos cuánto más mediatizados por esa forma invisible que constituye el verdadero motivo del conflicto: el poder. La telenovela por lo general, no plantea un conflicto de valores, sino una lucha por mantener el poder. Y es así como la imagen de la mujer, se convierte en un factor ideológico de innegable contenido político» (Osuna, 1984: 25). Llegamos entonces a un punto importante: el subtema de la telenovela (la que realmente tiene rating) es esa lucha política en la que se le da a la mujer un rol social de sumisión e inferioridad, ante el papel que desempeña el hombre dentro de la sociedad.

Ortega y Solsona (2000) resaltan los estudios de Modleski (1982), trabajo sobre narrativas femeninas populares que se convirtió en esencial a la hora de establecer un marco definitivo del discurso crítico de las soap operas. La investigadora sostiene que uno de los hechos que hace que la telenovela sea apreciada por la audiencia femenina es que el género se adapta muy bien a las tareas de las mujeres en el hogar, porque las telenovelas son repetitivas y no necesitan ser seguidas con una concentración continua; pero además, a diferencia de las radionovelas, éstas animan a dedicar un tiempo «para una», sentándose frente al televisor, y deteniendo por unos momentos las actividades 
domésticas. Modleski también destaca que las soap operas no representan familias ideales sino todo lo contrario, de manera que las mujeres se ven acompañadas por las protagonistas en sus mismos problemas familiares. En la misma línea sitúan el trabajo de Mary Ellen Brown (1995) quien se pregunta si las espectadoras pueden usar las telenovelas, y en particular las redes de «cotilleo», como un escalón más hacia la emancipación y como un catalizador del cambio social, o si, como se supone generalmente, las telenovelas refuerzan los valores culturales que mantienen a las mujeres en el lugar tradicional. Después de entrevistar a telespectadoras australianas de soap operas australianas, británicas y americanas desde 1986 a 1988, Mary Ellen Brown llega a la conclusión que es posible que algunos hombres y mujeres usen las conversaciones en los grupos de amistad sobre telenovelas para definir su espacio en el interior de una cultura que les deja poco lugar para constituir sus propias nociones de identidad.

En otro estudio, etnográfico de la novela Cañaveral de Pasiones, realizado por Villarruel (1998), se afirma que la diversidad de programas le permite complejizar su impacto social. Así, hay programas que refuerzan afinidades, gustos, identificaciones, otros que alientan la predilección por determinada actividad deportiva, otros más que promueven el gusto por ciertas actividades culturales, como los programas musicales, y otros valores relacionados con la vida cotidiana, como serían las telenovelas. A través de esta programación se reproducen dramas de la vida diaria cuya trama suele transmitir estereotipos que ayudan tanto al cambio como a la permanencia de roles y actitudes en los miembros de la familia. Conforme a esta premisa, consideramos que las telenovelas no sólo refuerzan roles de género en los miembros de la familia, sino también cambios en la feminidad y masculinidad.

\section{Investigación}

\subsection{Contextualización y justificación de la investigación}

Romero (1999) afirma que la investigación educativa no constituye hoy patrimonio exclusivo de los altos organismos oficiales, cada vez con mayor fuerza ésta se impone como una necesidad básica para el perfeccionamiento del profesorado, el desarrollo y evolución del currículum. Con la nueva Ley de Educación (LOE), la educación en 
valores queda reflejada, incluso incorporando nuevas asignaturas, como es Educación para la Ciudadanía. La Junta de Andalucía, ha aprobado también la Ley de Educación de Andalucía (LEA), quedando reflejado en el artículo 41 (competencias básicas de las enseñanzas obligatorias), en las que incluye:

- Competencia social y ciudadana, entendida como aquélla que permite vivir en sociedad, comprender la realidad social del mundo en que se vive y ejercer la ciudadanía democrática.

Esta misma Ley recoge en el artículo 42, la educación en valores e igualdad de género (2006: 43):

- Las actividades de las enseñanzas en general, el desarrollo de la vida de los centros y el currículo tomarán en consideración como elementos transversales el fortalecimiento de los derechos humanos y de las libertades fundamentales, los valores que preparan al alumnado para asumir una vida responsable en una sociedad libre y democrática, con espíritu de comprensión, paz, tolerancia, igualdad de los sexos y amistad entre todos los pueblos y grupos étnicos, nacionales y religiosos, así como la adquisición de hábitos de vida saludable y el respeto al medio ambiente.

- Con objeto de favorecer la igualdad real y efectiva entre hombres y mujeres, el currículo permitirá apreciar la contribución de las mujeres al desarrollo de nuestra sociedad y al conocimiento acumulado por la Humanidad.

El trabajo de investigación se centra en el estudio de la representación de los sexos que se ofrece a niños y niñas a través de la programación televisiva, concretamente de las telenovelas; una representación que contribuye a la supremacía masculina, que aleja a los varones de tareas domésticas, donde los varones sólo se dedican a actividades tradicionalmente masculinas, donde se usa la violencia como recurso de identidad masculina, etc. Concretamente, también pretende mostrar los hábitos de consumo televisivo de las niñas y niños del Centro «Francisco Alcalá» de Villalba del Alcor (Huelva), 
y sobre todo el consumo del género televisivo, la telenovela, género que está presente diariamente en casi todas las cadenas de TV; y a la vez señalar cómo la recepción de este género televisivo contribuye la desigualdad de género. Se trata, por tanto, de desarrollar la «competencia televisiva». Aguaded (1999: 273-4) hace referencia al estudio de Grégroire, quien establece cuatro dimensiones para desarrollar la competencia televisiva:

- «Una actitud de comprensión del fenómeno televisivo en todas sus dimensiones. (...) conocer y experimentar el proceso de producción de los mensajes, sus lenguajes, sus moldes y esquemas lingüísticos, sus significaciones».

- «Una actitud crítica» ('percepción orientada’). La recepción crítica implica no sólo recibir los mensajes sino interrogarlos, resituarlos, confrontarlos...

- «Una actitud selectiva»: seleccionar significa elegir conforme a unos valores.

- «Una actitud participativa», que suponga, también, la interacción y posterior apropiación del mensaje.

Para contextualizar nuestra investigación, seguimos a Aguaded (1999), que a su vez se basa Cambre y Zugner, quien apunta como principales perspectivas: la investigación básica que mide los efectos del medio o aspectos diversos de dichos efectos sobre una audiencia dada, los estudios de impacto que analizan la efectividad de programas o series tras un período de tiempo y la evaluación formativa que está dirigida específicamente a ayudar a los responsables de la creación de nuevos programas. La investigación, en este sentido, se enmarcaría dentro de los estudios de la investigación básica, ya que lo que se pretende es saber la influencia que un género televisivo, la telenovela, puede tener sobre una población determinada (niños y niñas de 11 y 12 años) desde una perspectiva de género.

\subsection{Objetivos de la investigación}

La finalidad y objetivo general del trabajo de investigación, es reflejar los hábitos de consumo del género telenovela en niños y niñas de 11 y 12 años; y a la vez cómo esa recepción contribuye o reafirma la desigualdad de género. De manera más concreta, los 
objetivos específicos que desarrollará la investigación pueden definirse en los siguientes términos:

1. Reflejar los hábitos de consumo de telenovelas de niñas y niños de once y doce años.

2. Describir los rasgos diferenciadores de género basados en la recepción de telenovelas.

3. Conocer la actitud de los padres ante la recepción televisiva de sus hijos.

4. Verificar que el consumo de este género televisivo (telenovela) es mayor por parte del género femenino.

\subsection{Procedimiento del estudio}

El proceso investigador lo concretaremos siguiendo las siguientes fases, teniendo en cuenta que éstas guiarán nuestro estudio para proporcionarle una estructura lógica y de rigor.

1. Revisión de la literatura: Se realiza una revisión bibliográfica sobre la educación en valores en la escuela, la familia y en los medios de comunicación, centrándonos en la igualdad de género, así como en el mundo de las telenovelas. Para ello empleamos una bibliografía especializada como son los libros, revistas y artículos. Las referencias las tomamos de distintas universidades, accediendo a través de la Universidad de Huelva, utilizando para ello los préstamos interbibliotecarios. Éstas se tomaron del castellano (tanto de textos del ámbito peninsular, como de la copiosa documentación que en esta especialidad 'la telenovela', existe en Iberoamérica), del ámbito francófono y anglófono.

2. Elaboración del diseño de investigación: Ésta se ha ido adaptando a las circunstancias contextuales.

3. Negociación para el acceso al campo: A comienzos del curso 2006-07, planteamos al equipo directivo y a los tutores de $5^{\circ}$ y $6^{\circ}$ nuestra propuesta de investigación, mostrando una actitud favorable al respecto, así como interés por el tema, ya que el centro tiene pensado implicarse en algún proyecto de coeducación. 
4. Desarrollo y aplicación de la investigación en el centro: Durante el mes de Enero se procede a pasar los cuestionarios a los alumnos del tercer ciclo de Educación Primaria.

5. Tratamiento estadístico de los datos: El análisis de los datos de los cuestionarios se realiza mediante el paquete informático SPSS.

6. Conclusiones e implicaciones de nuestro trabajo de investigación: A partir del análisis y valoración de los datos generados, con el objeto de demostrar la consecución o no de los objetivos propuestos.

7. Redacción del informe final del estudio.

En la investigación, los resultados obtenidos no tienen pretensión de generalización ni extrapolación, se circunscriben a los contextos analizados, manteniendo unos criterios de inclusión y exclusión precisos. Es por ello que para el estudio hemos optado por muestras no probabilísticas, que emplean métodos de razonamiento para construir la muestra. En nuestro caso, hemos seleccionado los alumnos del tercer ciclo de Educación Primaria, sin seguir criterios probabilísticos, sino un muestreo de elección razonada (Aguaded, 1999). Sin generalizar ni extrapolar los resultados, la investigación sí puede servir de referencia para analizar y comprobar la situación actual del tema tratado, además de verificar la influencia de la televisión en los niños y niñas.

El tamaño de la muestra es de 48 alumnos del tercer ciclo de Educación Primaria, de los cuales, 21 son de sexto nivel y 27 de quinto curso.

\subsection{Los cuestionarios}

En función de las pretensiones de esta investigación y la literatura que hemos revisado, como estrategia de recogida de datos se emplea el cuestionario como instrumento para responder a los objetivos planteados en el trabajo de la forma más fielmente posible.

El interior del cuestionario ofrece cuatro páginas con 28 cuestiones, las cuales abarcan distintos ámbitos:

a) Datos descriptivos, tales como la edad, curso y sexo. 
b) Hábitos de consumo televisivo: programas favoritos, personajes favoritos, etc.

c) Actitud de los padres ante la recepción televisiva: programas prohibidos, consejos, etc.

d) Consumo de telenovelas: telenovelas conocidas, favoritas, etc.

e) Diferencias de género en la recepción de telenovelas: personajes preferidos, no favoritos, etc.

\subsection{Los resultados}

Entre otros resultados, destacamos como significativos el considerar las telenovelas como el programa estelar y favorito, con un 41,7\% de preferencia, ocupando un segundo lugar los dibujos animados con un 20,8\%, prácticamente la mitad del primero. Los niños y niñas consumen de forma general este género televisivo, en gran parte como su favorito.

PROGRAMA FAVORITO EN PRIMER LUGAR

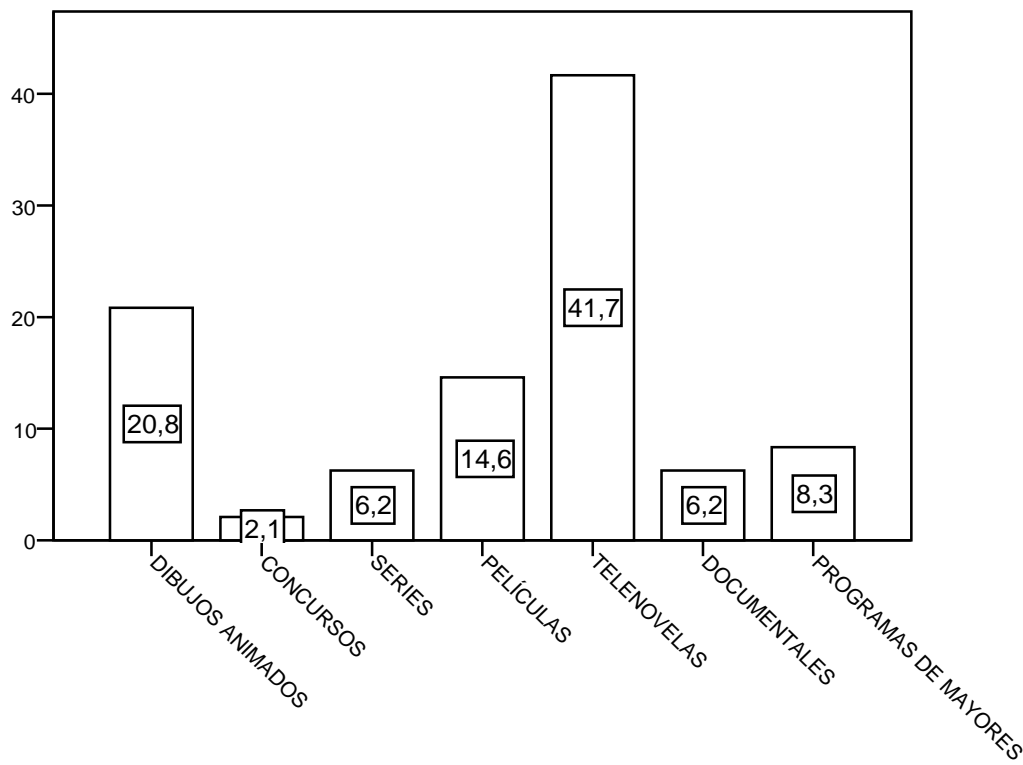

Ahora bien, si tenemos en cuenta la última dimensión a analizar de este trabajo de investigación, que es la afirmación del género, bajo los resultados de este ítem se 
ocultan diferencias de género muy significativas, ya que podemos interpretar que las telenovelas es un género televisivo «pensado» para las mujeres, como resaltan algunos estudiosos del tema, ya que del $41,7 \%$ que han elegido a éste como programa favorito, el $40,7 \%$ son niñas y tan sólo un 7,1\% son niños, mientras que los niños se decantan por los dibujos animados y las películas. También es significativo que haya niños que eligen programas de mayores y en las niñas no. Podemos deducir que los niños buscan la transgresión de las normas, lo prohibido, lo no apto para ellos, rasgo estereotípico asociado a la masculinidad.

Las niñas prefieren las telenovelas, ya que casi todas, a excepción de dos alumnas, han elegido alguna telenovela como programa favorito, y aunque los alumnos también han optado por ella, se decantan preferentemente por los dibujos animados.

PROGRAMA FAVORITO
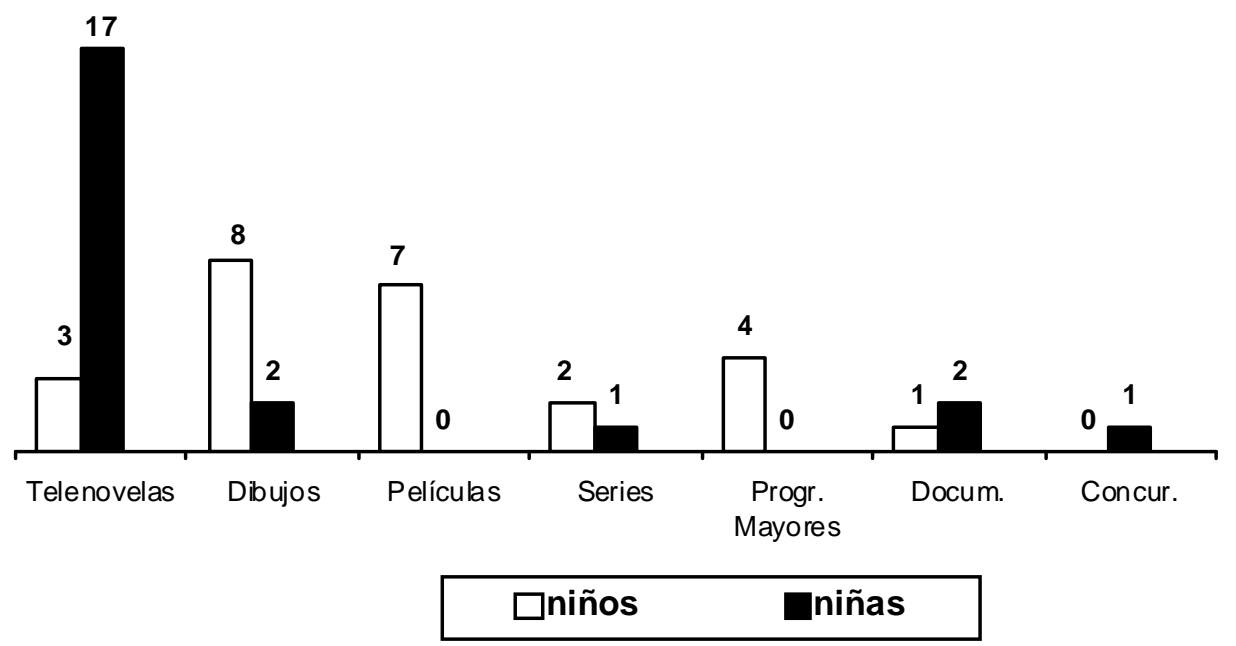

El programa que más les gusta resulta ser una telenovela que ha arrasado en índices de audiencia, Pasión de Gavilanes, con un 50\%. Por otro lado, resaltamos que aunque con un porcentaje más bajo, en el gráfico aparecen otras dos telenovelas, Los Plateados y La Tormenta. Por tanto, se confirma y a la vez reafirma que los niños y niñas ven telenovelas, señalando incluso cuáles son éstas. Por otra parte, en este ítem al realizar un análisis desagregado por género, se detectan diferencias muy interesantes, ya que éstas reafirman lo expuesto en el ítem anterior. 


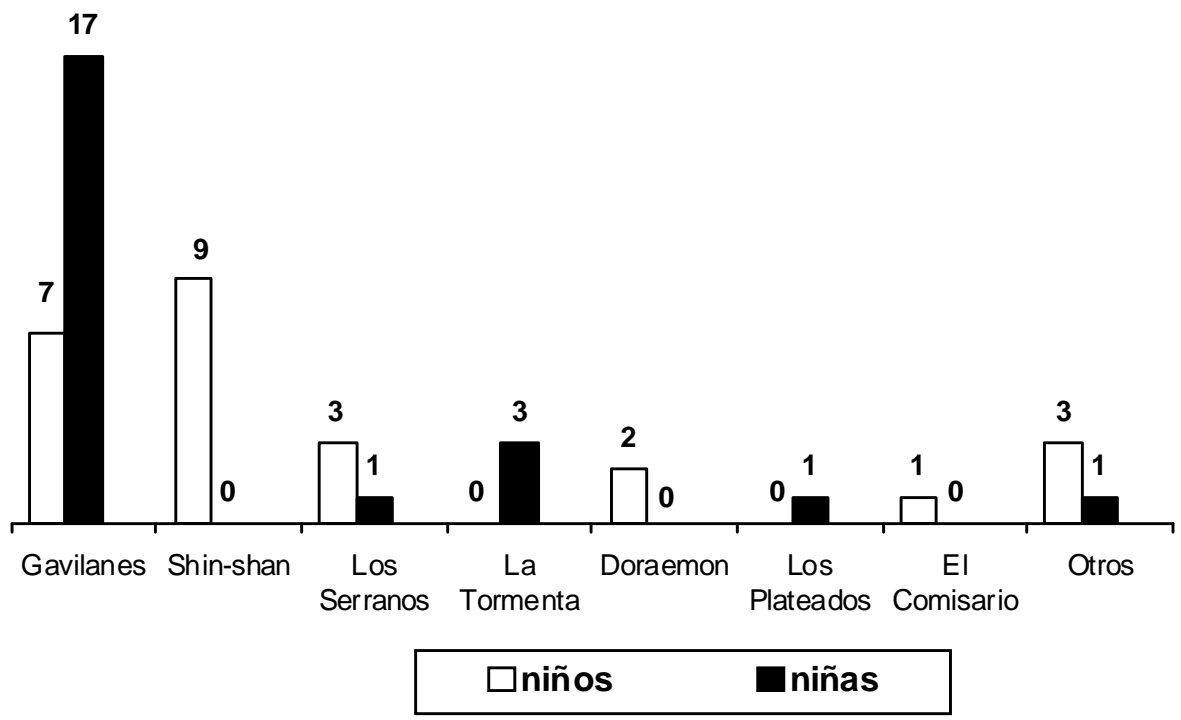

Pero dado que es el género, uno de los objetivos de estudio de nuestro trabajo de investigación, uno de los bloques de preguntas del cuestionario estaba dirigido a profundizar sobre éste. Así en el ítem 15 se pretendía recoger qué telenovelas conocían los niños y niñas.

\begin{tabular}{|lc|}
\hline \multicolumn{2}{|c|}{ ¿Conoces algunas de estas telenovelas? } \\
PELENión de Gavilanes & TOTAL \\
Arrayán & $85,40 \%$ \\
El cuerpo del deseo & $81,25 \%$ \\
Amarte así & $62,50 \%$ \\
Rubí & $60,42 \%$ \\
La Tormenta & $56,25 \%$ \\
Los Plateados & $52,08 \%$ \\
El auténtico Rodrigo Leal & $47,92 \%$ \\
Amar en tiempos revueltos & $45,83 \%$ \\
Betty la fea & $39,58 \%$ \\
Obsesión & $29,17 \%$ \\
Otros & $16,67 \%$ \\
\hline
\end{tabular}


Otro aspecto resaltable y de interés en cuanto a la diferenciación por géneros, se observa que no existen grandes diferencias entre niños y niñas a la hora de elegir la compañía con la que han visto su telenovela favorita, ya que ambos sexos prefieren estar junto a sus madres, o bien son éstas las que consumen mayormente las telenovelas, y los niños y niñas aprovechan para verlas también.

\section{Veo las telenovelas con...}

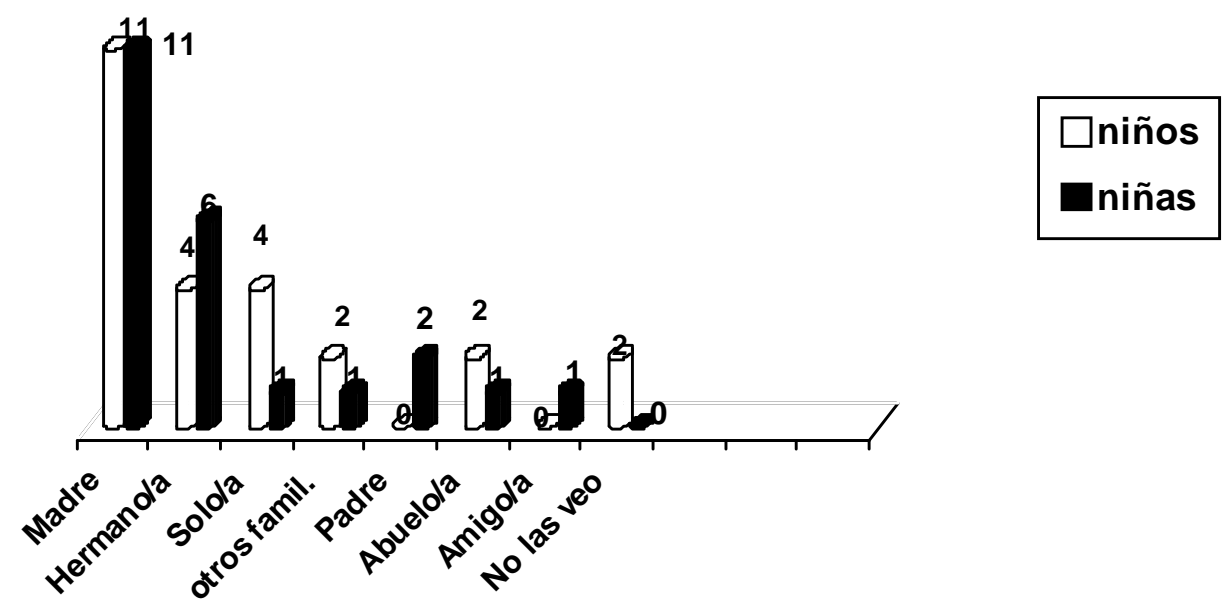

En el caso del grupo niños, el grupo de cualidades de sus personajes favoritos es igualmente significativo e interesante para las pretensiones del trabajo de investigación. Así, éstos además de valorar el aspecto físico agradable, con un alto porcentaje, aprecian la profesionalidad y la agresividad, grupo de cualidades que no han seleccionado ninguna niña. La acción, agresividad, violencia, son pilares estereotípicos sobre los que se ha construido simbólicamente la masculinidad, por lo que es comprensible que no aparezca en el grupo de cualidades preferidas por las niñas. 


\begin{tabular}{|c|c|c|}
\hline \multicolumn{3}{|c|}{ Cualidades de los personajes favoritos } \\
\hline Cualidades relacionadas con: & Niños & Niñas \\
\hline ASPECTO FÍSICO AGRADABLE & $40 \%$ & $60,83 \%$ \\
\hline PROFESIONALIDAD & $24 \%$ & $0 \%$ \\
\hline AGRESIVIDAD & $32 \%$ & $0 \%$ \\
\hline HUMOR & $4 \%$ & $13,04 \%$ \\
\hline HABILIDADES SOCIALES & $0 \%$ & $26,09 \%$ \\
\hline
\end{tabular}

\subsection{Conclusiones}

Si se tiene en cuenta que un porcentaje de niños y niñas ven la televisión en horarios (mediodía/tarde) donde son más frecuentes las emisiones de telenovelas; que es el tipo de programa más permitido por los padres a la hora de su visión; que el 60,4\% tienen TV para ellos solos y por tanto aunque se lo prohíban pueden que no lo cumplan; es evidente que los niños y niñas lo tienen muy fácil para consumir este género televisivo, como ha quedado demostrado, con un 41,7\%, más del doble del segundo programa televisivo favorito elegido. Además, telenovelas de gran éxito y audiencia adulta como Pasión de Gavilanes, ha resultado tener semejante audiencia en la población infantil de esta investigación, con un 50\%. A esto le sumamos el 8,3\% que han optado por otras telenovelas, y comprobamos que un 58,3\% han elegido telenovelas como programas favoritos. Todo esto se ha confirmado aún más, cuando además se ha indagado en sus personajes favoritos de la programación televisiva en general, ocupando personajes de telenovelas el $68,7 \%$ frente al 31,5\% que han elegido otros personajes del mundo televisivo.

Del análisis de los hábitos de consumo de telenovelas, en la interiorización de la representación de géneros se concluye que: 
- La representación de personajes masculinos favoritos es mayor que la de personajes femeninos. Los niños y niñas encuestados eligieron como favoritos a una mayoría de personajes masculinos, el 70,8\%, frente al 29,1\% de personajes femeninos.

- Las niñas valoran más a estos personajes favoritos por el aspecto físico y agradable (modelos de cuerpos muy vendidos en los medios de comunicación, al que muchas niñas quieren imitar) y las cualidades de habilidad social.

- Los niños, aunque también resaltan el aspecto físico agradable, es más compartido con otras cualidades que no aparecen el grupo femenino encuestado, como son la agresividad y la violencia, estereotipos masculinos. Por tanto, el refuerzo estereotípico de género muestra su influencia en la socialización diferencial de género.

- Se penaliza más a los personajes femeninos, especialmente por parte de los niños, con un 60\%, pero también de forma importante por parte de las niñas, con un $40 \%$.

- Penalizan la transgresión al modelo femenino conforme a las pautas de género. De igual manera, se penaliza las rupturas con los modelos que ejemplifican la masculinidad (débil, tontón, etc.).

- Las niñas prefieren las telenovelas a los dibujos animados, que son los preferidos por los niños. En las telenovelas siempre está presente la temática sentimental, preferida por las niñas, ya que los niños optan por los temas de acción, aventura, etc., que se dan en los dibujos animados.

- Por otro lado, de los programas prohibidos, la telenovela ha resultado ser junto con el género policíaco, los más permitidos por parte de los padres y madres a sus hijos e hijas a la hora de visionar programas televisivos, con un 54,2\% cada uno de ellos.

- Por otra parte, al disponer de TV gran parte de éstos, para ellos solos, el control de programas resulta más complicado.

- Aunque ha quedado demostrado que tanto los niños como las niñas de esta investigación consumen telenovelas, el grupo femenino lo hace en mayor proporción que el masculino, con un 40,7\% frente al 7,1\%. Los niños se decantan por los dibujos animados y las películas.

- Si tenemos en cuenta que en los programas concretos o específicos que han resultado favoritos, se vuelve a constatar lo anteriormente expuesto, ya que del $50 \%$ 
que han elegido la telenovela Pasión de Gavilanes como programa favorito, el $35,4 \%$ son niñas, frente al $14,5 \%$ que son niños.

- Por otro lado, la realización de este trabajo de investigación nos ha llevado a conocer que son sus madres, las mayores consumidoras de telenovelas en sus casas, con un $56,2 \%$ frente a un $4,1 \%$ de padres, por lo que además de ser consumida por la mayoría de las niñas de este estudio, lo es también por el sexo femenino adulto.

En definitiva, y entre otras conclusiones finales del trabajo, se puede confirmar de forma genérica que los niños y niñas, sujetos de este trabajo de investigación y que pueden servir de referencia para conocer la situación en otros contextos, consumen telenovelas y al mismo tiempo esa recepción está influyendo y afirmando la socialización diferenciada de género.

\section{Referencias}

AGUADED, J.I. (1993). Comunicación audiovisual en una enseñanza renovada. Huelva: Comunicar Ediciones.

AGUADED, J.I. (1999). Educación para la competencia televisiva. Fundamentación, diseño y evaluación de un programa didáctico para la formación del telespectador crítico y activo en Educación Secundaria. Huelva, Universidad de Huelva.

AGUADED, J.I. (1999b). Convivir con la televisión. Familia, educación y recepción televisiva. Barcelona: Paidós.

BALLETBÓ, A (1984). «La mujer en los medios de comunicación social». En: Revista Leviatán. Madrid.

BROWN, M.E. (1995). «Melodramas televisivos y conversaciones de mujeres: La posibilidad de lecturas emancipadoras». En: PEÑAMARÍN, C. \& LÓPEZ DÍEZ, P. (coord.). Los melodramas televisivos y la cultural sentimental. Madrid: Universidad Complutense, Instituto de Investigaciones Feministas.

CHARLES, M. (2002). «La televisión y la construcción de género». En: II Congreso de Imagen y Pedagogía, Mazatlán, Sinaloa; noviembre.

FROUFE, S. (1998). «Familias y medios de comunicación». En: Comunicar, 10, p. 2126. 
JUNTA DE ANDALUCÍA (Ed.) (2006). Anteproyecto de Ley de Educación de Andalucía. Sevilla: Consejería de Educación de la Junta Andalucía.

JUNTA DE ANDALUCÍA (Ed.) (2005). I Plan de Igualdad entre Hombres y Mujeres en Educación. Sevilla: Consejería de Educación de la Junta de Andalucía.

LIZAUR, B. (1999). «La telenovela como melodrama y su aprovechamiento pedagógico». En: ILCE (Ed.). Curso uso pedagógico de la televisión. México: ILCE.

MAISCH, G. (1999). «Los discursos de género en la juventud peruana y la experiencia comunicativa de andamios», en La Ventana, 10. México.

MARCH, J.C. y GARCÍA, M. (1994). «Infancia y medios de comunicación. Nacidos con la tele». En: La Generación TV. Granada: Escuela Andaluza de Salud Pública, p. 29-32.

MODLESKI, T. (1982). Living with a vengeance. Nueva York: Methuen.

MOLINA, X. y CARVAJAL, L. (1999). «Trayectoria de la telenovela latinoamericana: el caso de telenovela brasileña». En: La Latina, 21, septiembre.

MUÑOZ, C.; ASQUETA, M.C. y MARTÍNEZ, B. (2004). «La telenovela: ¿Ritualización antidemocrática del espacio público». En: Ritualización antidemocrática del espacio público: La telenovela. Universidad Minuto de Dios.

MUÑOZ, A. y GUERREIRO, B. (2001). «Materiales previos. Conclusiones del Grupo de trabajo: Sexo y género en la educación». En: Congreso Construir la escuela desde la diversidad y para la igualdad.

ORTEGA, M. y SOLSONA, M. (2000) «Demografía, cambio familiar y telenovelas. De la realidad a la representación y viceversa», en La familia en Cataluña. Continuidades y cambios. Centre d’ Etudis Demográfics.

OSUNA, Y. (1984). «Imagen de la mujer en la telenovela». En: Comunicación, 47.

PÉREZ ALONSO, P. (1994). «Tiempo de ocio y televisión en la infancia y adolescencia», en RADIOTELEVISIÓN VALENCIANA (Ed.). Televisión. Niños y jóvenes. Valencia: RTVV, p. 175-198.

ROMERO CARMONA, J.B. (2005). «Televisión y adolescentes: una crítica y controvertida relación». En: Comunicar, 25, p. 147-151.

SANDER, E. (1990). «Los medios de la comunicación en la vida cotidiana de la familia. Relación generacional y cultura juvenil». En: Infancia y Sociedad, 3; 19-29. 
VILCHES, L. (1997). «La fuerza de los sentimientos», en VERÓN, E. y ESCUDERO, L.: Telenovela, ficción popular y mutaciones culturales. Barcelona: Gedisa.

VILLARRUEL, C. (1998). «De cómo las telenovelas transmiten lo femenino: un estudio etnográfico de la novela Cañaveral de Pasiones». En: Educar, 7; octubrediciembre. 